\title{
Sofrimento psíquico e social na situação de desemprego ${ }^{1}$
}

\author{
Maria Luiza Gava Schmidt², Caio Augusto Rodrigues Martins Januário ${ }^{3}$ e \\ Liliane Ubeda Morandi Rotoli ${ }^{4}$ \\ Universidade Estadual Paulista (Assis, São Paulo, Brasil)
}

Esta pesquisa visou identificar fatores de sofrimento psíquico-social em desempregados. A coleta de dados foi realizada no Posto de Atendimento ao Trabalhador localizado num município do estado de São Paulo. Um Questionário Sociodemográfico e a escala para avaliação de sofrimento psíquico-social de trabalhadores desempregados foram utilizados para coleta de dados. Dos 100 respondentes, 57\% são homens e 43\% são mulheres, na faixa etária de 19 a 41 anos, com tempo médio de desemprego de 11,7 meses. A escala apresentou a média dos itens que correspondem ao sofrimento psíquico igual a 3,32 (desvio padrão = 1,29), com variação entre "às vezes" e "frequentemente" para aspectos como insegurança, medo e vergonha, enquanto a média do sofrimento social foi de 1,84 (desvio padrão $=0,98$ ), variando entre "raramente" e "às vezes" com indicadores de suporte social de familiares e amigos. Os resultados revelaram a vivência do desemprego por parte dos respondentes e apontou para a necessidade de ações da psicologia nas áreas social, de trabalho e clínica voltadas a auxiliar nos impactos provocados pelo desemprego bem como a criação de políticas públicas para diminuir o impacto da recessão.

Palavras-chave: Desemprego, Precarização do trabalho, Sofrimento psíquico e social, Psicologia social e do trabalho.

Psycho and social suffering in unemployment situations

This study aimed to identify psychic and social suffering factors in unemployed individuals. Data collection was conducted at a Center of Services to Workers located in a municipality in the state of São Paulo. A Sociodemographic Questionnaire and the instrument to assess psycho-social suffering in unemployed workers were used for data collection. Out of 100 respondents, $57 \%$ are men and $43 \%$ are women, aged between 19 and 41 , with mean unemployment time of 11.7 months. The instrument presented the mean of the items that correspond to psychic suffering equal to 3.32 (standard deviation = 1.29), with variation between "sometimes" and "often" for aspects such as insecurity, fear and shame, while the mean of social suffering was 1.84 (standard deviation = 0.98), varying between "rarely" and "sometimes" with social support indicators from family members and friends. The results revealed the experience of unemployment on the part of respondents and pointed to the need for psychology actions in the social, work and clinical areas aimed at assisting the impacts caused by unemployment as well as the creation of public policies to reduce the impact of recession.

Keywords: Unemployment, Work precariousness, Psychic and social suffering, Social and work psychology.

\section{Introdução}

$\mathrm{N}$ as últimas décadas, o desemprego tem sido mundialmente discutido, sendo foco de um número expressivo de estudos e publicações, talvez mais do que em qualquer outra época, pelo fato de ser um dos mais importantes aspectos da precariedade social na sociedade capitalista (Bernardo, Nogueira \& Büll, 2011; Druck, 2011), com repercussões individuais e coletivas (Barros \& Oliveira, 2009), associadas à perda das identidades (Druck, 2011), "não sendo possível de ser evitado nem mesmo nos países de capitalismo mais avançado” (Mészáros, 2006, p. 29).

1 Informamos que este artigo faz parte da pesquisa de Iniciação Científica de Caio Augusto Rodrigues Martins Januário, a qual recebeu Bolsa Fapesp (processo 2017/06694-5) . Foi orientada pela docente Maria Luiza Gava Schmidt e a análise estatística dos dados foi auxiliada pela professora Liliane Ubeda Morandi Rotoli.

2 Docente do curso de graduação em Psicologia Universidade Estadual Paulista "Júlio de Mesquita Filho", Faculdade de Ciências e Letras, Departamento de Psicologia Experimental e do Trabalho.

3 Graduado em Psicologia pela Universidade Estadual Paulista "Júlio de Mesquita Filho", Faculdade de Ciências e Letras.

4 Professora Substituta Universidade Estadual Paulista "Júlio de Mesquita Filho". 
Concebido como falta ou ausência de trabalho, seguida pela busca dele, mediante a disponibilidade para trabalhar (Oliveira \& Mendes, 2014), o fenômeno no Brasil tem apresentado indicadores elevados nos últimos anos. A força de trabalho brasileira é regularmente estimada pelo Instituto Brasileiro de Geografia e Estatística (IBGE). Entre os indicadores, destaca-se a Pesquisa Nacional por Amostra de Domicílios Contínua (Pnad). A Pnad trimestral de 2017 indicou queda na taxa de desempregados no Brasil, de $13,7 \%$ para $11,8 \%$. No primeiro trimestre de 2018 , a taxa atingiu o percentual de $13,1 \%$ da força de trabalho e, no segundo trimestre, houve uma queda para $12,4 \%$. Nas últimas pesquisas, em média, o maior percentual da população desocupada corresponde às mulheres, indivíduos com escolaridade de pelo menos o ensino médio, de cor negra (Instituto Brasileiro de Geografia e Estatística [IBGE], 2018).

De acordo com Pochmann (2006), o desemprego no Brasil tem aumentado continuamente desde 1990, sofrendo alterações em seu perfil, passando de um fenômeno homogêneo com impactos em seguimentos específicos como mercado de trabalho - mulheres, jovens, negros e pessoas sem qualificação profissional - e se transformando num fenômeno heterogêneo, atingindo de forma generalizada praticamente todos os seguimentos sociais.

Enriquez (1999) ressaltou que, diante do fenômeno decorrente da perda de emprego, sustentava-se a tese de que a economia capitalista se comportaria melhor, entretanto, o que se observava era que a redução de empregos, devido às novas tecnologias - como por exemplo a reengenharia e técnicas de qualidade total - impactavam no crescimento global em todos os países. Nesse contexto, o autor alertou que, pelo fato de o trabalho ser elemento constitutivo do ser humano e importante para sua estruturação psíquica, a perda deste provocaria a perda da identidade, concorrendo para a degradação da personalidade (Enriquez, 1999).

Para Antunes (2004), o trabalho é concebido como um aspecto central para a sociabilização dos sujeitos. Também é compreendido como ato de produção e reprodução na relação do indivíduo com a natureza e o contexto promissor para o desenvolvimento de suas potencialidades (Navarro \& Padilha, 2007). No entanto, com as novas exigências conferidas a ele, tem-se a desestabilização dos trabalhadores estáveis, a instalação da precariedade do trabalho, o desemprego (composto por aqueles que seriam capazes de trabalhar e não o fazem), conforme descrito por Castel (1998). Desse modo, é denominado desempregado o indivíduo que vivencia "a falta de renda, a exclusão do mundo trabalho e que vive à margem da sociedade, por não ser reconhecido como um cidadão ativo e produtivo" (Pinheiro \& Monteiro, 2007, p. 42).

O impacto do desemprego na deterioração do bem-estar psicológico dos trabalhadores, em razão da situação de desemprego, tem sido destacado por pesquisadores (Argolo \& Araújo, 2004). A situação é preocupante pois "o desemprego força as pessoas, desesperadas pela falta de dinheiro e de reconhecimento social, a enfrentarem filas aviltantes para tentar uma vaga no mercado do emprego formal, mesmo que este seja alienado e estranhado" (Navarro \& Padilha, 2007, p. 19). Assim, "ficar desempregado pode significar não só uma suspensão da estabilidade econômica, mas também uma exposição de cada um e de todos nós diante de si e da sociedade, colocando certezas em xeque" (Terra, Carvalho, Azevedo, Venezian \& Machado, 2006, p. 50).

Essa nova questão social, marcada pelo desemprego, colabora para a emergência de três processos: a desestabilização dos estáveis, a instalação da precariedade e o déficit de lugares, os quais produzem efeitos negativos "à identidade de todos aqueles que a tiveram forjada sobre a questão do trabalho, gerando sofrimento e, ainda, a possibilidade de autodestruição" (Werlang \& Mendes, 2013, p. 750). Para Antunes (2011), essa destrutividade "se expressa intensamente quando descarta, tornando ainda mais supérflua, parcela significativa da força mundial de trabalho, onde milhões encontramse realizando trabalhos parciais, precarizados na informalidade ou desempregado" (p. 407). 
Em razão das consequências negativas do não-trabalho, estudos apontam a emergência de sofrimento social e psíquico, os quais podem produzir repercussões à saúde mental dos indivíduos que se encontram fora do mercado de trabalho. De acordo com Werlang e Mendes (2013), o sofrimento social:

Se instala/esconde nas zonas de precariedade, nas zonas sociais de fragilidade e cuja ação implica na perda ou possibilidade de perda dos objetos sociais: saúde, trabalho, desejos, sonhos, vínculos sociais, ou seja, o todo da vida composto pelo concreto e pelo subjetivo que permite o viver (p. 743).

No que tange ao desemprego, o sofrimento social emerge do desligamento do indivíduo do social, uma vez que se encontra enfraquecido pela vivência da precarização, num estado de desfiliação social conforme denominado por Castel (1998). Druck (2011) também assevera que a perda do emprego é responsável pela emergência do sentimento de insegurança em decorrência da ruptura dos vínculos, tornando os desempregados vulneráveis mediante a condição social fragilizada.

Nessa conjuntura, o termo "sofrimento social" foi cunhado justamente para expressar uma dor que não é localizada. Como expressa Furtos (2008), "é uma dor da existência”, que emana dos sentimentos de solidão, desamparo e medo. Somado a esses, o autor atenta também para o surgimento do medo da perda ou a perda, um elemento, segundo ele, importante na análise da situação do desemprego, posto que o emprego é um objeto social concreto e sua perda gera insegurança, lembrando que a segurança é um fator fundamental de saúde mental (Furtos, 2007). Por sua vez, o medo contribui para a intensificação da submissão e do sofrimento do trabalhador (Aucher \& Barnier, 2015).

Ademais, a falta de emprego é uma situação geradora "de negação, dor, ausência de reconhecimento, sentimento de relegação e de inutilidade e, ainda, um sentimento de rebaixamento, uma vez que o sofrimento introduziria um hiato importante entre a percepção de si e as normas sociais que o suportam" (Werlang \& Mendes, 2013, p. 754). Diante das dificuldades de reconhecimento e pertencimento a um determinado grupo social, o indivíduo entra em estado de precariedade psíquica, sendo o sofrimento psíquico um indicador dessa mesma precariedade (Jacques, 2004). Do mesmo modo, Dejours (2003) concebe que o indivíduo desempregado, ao não conseguir trabalho, passa por um processo de dessocialização progressiva, fonte de intenso sofrimento.

Nessa direção, Figueiredo e Nascimento (2015) compreendem que sofrimento psíquico relacionado ao desemprego, decorrente de buscas frustradas por uma colocação, somado à sensação de instabilidade e insegurança, maior competitividade, individualidade e luta exasperada pela sobrevivência, é acrescido ao medo de não conseguir se inserir novamente no mercado de trabalho e perder de vez seu poder de compra, seu próprio sustento e de sua família.

De acordo com Abs e Monteiro (2010), as experiências negativas vividas por pessoas desempregadas são compostas de sofrimento e psicopatologias, pois a situação de desemprego cria consequências negativas,

Como a desestruturação de laços sociais e afetivos que restringem os direitos, tornando a insegurança socioeconômica, a redução da autoestima, o sentimento de solidão e fracasso em fardos que os indivíduos carregam, resultando em desenvolvimento de distúrbios mentais, bem como a geração de consumo ou dependência de drogas (Pinheiro \& Monteiro, 2007, p. 42).

Entre os estudos que têm apontado que o desemprego pode afetar a saúde do indivíduo desempregado, a pesquisa realizada por França et al. (2017) mostrou que: 
Os transtornos mentais, especialmente transtornos de humor estão associados à inatividade ou ao desemprego entre os homens e à inatividade entre as mulheres, com exceção aos transtornos devido ao uso de substâncias psicoativas que também estão associados ao desemprego em as mulheres” (p. 1).

Os autores observaram também que a busca por serviços de saúde entre os portadores de transtornos mentais é menos frequente entre os desempregados.

Dimas, Pereira e Canavarro (2013) verificaram que o desemprego de longa duração causa sintomas de depressão, e que os indivíduos de idade entre 29 e 37 anos são mais propensos a desenvolverem esses sentimentos. Isso decorre, sobretudo, porque o trabalho confere sentidos que vão além do caráter da satisfação básica e, por ocupar uma posição importante na vida do indivíduo, tem sido associado também a formas de identificação e autoestima, meio de inclusão na sociedade contemporânea.

Ademais, são apontadas como sequelas do desemprego algumas alterações no bem-estar psicológico, entre as quais se destacam: transtornos mentais leves, dificuldades de relacionamento familiar, insatisfação com a vida e degradação da autoestima. Dessa forma, o trabalhador desempregado vivencia um processo de deterioração advindo da inatividade, cuja ressignificação só poderia ser contestada com a provisão de um novo trabalho (Argolo \& Araújo, 2004). Pesquisa aponta também que a capacidade de resiliência do desempregado está associada a menor sintomatologia psicopatológica, a melhor percepção de qualidade de vida, além de melhor ajustamento diádico (Dimas et al., 2013).

Para Dejours (1992), a situação expõe a identidade do trabalhador na sociedade atual, em que o trabalho é excessivamente valorizado e concebido como um dever moral. Em sua obra $A$ loucura do trabalho: estudo em psicopatologia do trabalho, há uma lista de psicopatologias do trabalho, tais como: da sobrecarga, do estresse pós-traumático, do assédio moral, do suicídio e tentativas, dos vícios e drogadição e a do desemprego. Essa última, na opinião do autor, está muito ligada à questão da perda (do emprego, do salário, da atividade e do status, dos laços sociais, do sentimento de utilidade etc.). Segundo ele, os indivíduos presentes nesse quadro podem enfrentar problemas de humor (como a depressão) ou de comportamento (raiva, agressividade).

Mediante essas considerações sobre os efeitos deletérios do desemprego à saúde do indivíduo, justifica-se a realização desta pesquisa, posto que o Brasil enfrenta, neste momento, um índice significativo de pessoas desempregadas, além do alto contingente de situações precárias de trabalho relacionadas ao contexto social gerador do desemprego. Assim sendo, visou-se a identificar fatores de sofrimento psíquico-social nesse grupo de indivíduos.

\section{Método}

Tratou-se de pesquisa quantitativa, descritiva e de corte transversal. Foram analisados os dados de 100 desempregados que buscaram o Posto de Atendimento ao Trabalhador (PAT) de um município localizado no interior do estado de São Paulo, no período de julho a dezembro de 2017.

Foram consideradas desempregadas as pessoas que estavam sem exercer atividade laboral com vínculo formal decorrente da demissão nos últimos três meses do momento da coleta de dados, foram incluídos também as que estavam exercendo trabalhos irregulares ou informais, e procuravam mudar essa situação no momento da pesquisa. Foram excluídos trabalhadores que estavam desempregados há menos de três meses, após terem trabalhado com carteira assinada.

Este estudo seguiu as diretrizes e normas regulamentadoras de pesquisas envolvendo seres humanos, definidas pela Resolução n 196/96 do Conselho Nacional de Saúde, e foi aprovado. 
O projeto foi iniciado após aprovação no Comitê de Ética em Pesquisa e está registrado na Plataforma Brasil CAAE n 66705817.4.0000.5401.

Procedimentos de coleta de dados

O contato inicial com as participantes foi realizado durante o momento de preenchimento da ficha cadastral. Aqueles dispostos a colaborar com o estudo foram informados sobre os objetivos e etapas da pesquisa, obedecendo às exigências éticas pertinentes como a privacidade, o anonimato e o preenchimento do Termo de Consentimento Livre e Esclarecido (TCLE).

Os participantes responderam a um questionário sociodemográfico, composto por questões fechadas, com dois blocos: variáveis sociodemográficas (idade, sexo, estado civil, escolaridade, renda familiar, número de filhos, número de pessoas que moram na residência do participante, se é provedor da família, religião); e situação de desemprego (tempo de desemprego, sentimentos e dificuldades relacionados ao desemprego e recebimento ou não de seguro-desemprego).

$\mathrm{Na}$ sequência, responderam a escala para avaliação de sofrimento psíquico-social de trabalhadores desempregados (EASPSTD), desenvolvida por Veiga e Silva (2007). Essa escala é constituída por dois fatores - sofrimento psíquico e sofrimento social -, os quais foram avaliados em duas dimensões. Ela é do tipo Likert, com cinco pontos que correspondem a: nunca, raramente, às vezes, frequentemente e sempre.

O fator sofrimento psíquico é composto por oito itens, cujo conteúdo se refere às vivências internas relacionadas ao desemprego, como ansiedade, angústia, estresse, tristeza e desânimo. O sofrimento social é composto por sete itens, referentes às alterações no relacionamento familiar e à exclusão social do trabalhador desempregado. A dimensão relativa ao fator sofrimento psíquico corresponde às questões ímpares da escala $(1,3,5,7,9,11,13$ e 15), ao passo que a dimensão sofrimento social é constituída pelas questões pares da escala (2, 4, 6, 8, 10, 12 e 14).

Para a realização da coleta de dados, foram realizadas visitas ao PAT, quatro vezes por semana, com exceção em feriados e dias de atividades internas, perfazendo, no período, 57 visitas no total.

Procedimento de análise

O conteúdo dos dados foi digitado em planilha Excel e avaliado com base nos dados de natureza quantitativa, amparado nos repertórios estatísticos de variáveis, frequências, médias e desvio padrão. Por fim, foram analisados com o apoio de bibliografia pertinente e em razão dos objetivos da pesquisa.

\section{Resultados e discussão}

Do total de 100 respondentes, 57\% são homens e 43\% são mulheres. O tempo médio de desemprego encontrado foi de 11,7 meses. Vale destacar que o tempo de desemprego interfere diretamente na subjetividade do trabalhador e, quanto maior o tempo, maior a tendência ao acúmulo das cobranças e frustrações.

Observou-se maior concentração na faixa etária de 19 a 41 anos, sendo essa idade período característico da vida ativa das pessoas em emprego. Os dados apresentaram também características do "desemprego de reestruturação", ou seja, o que atinge trabalhadores entre 25 e 50 anos de idade e que trabalham em setores econômicos que estão se reestruturando (Caldana \& Figueiredo, 2002). 
Os resultados evidenciaram o perfil etário da desocupação entre os mais jovens, convergindo com as preocupações do ponto de vista social e econômico apontadas por Simões, Alves e Silva (2016) de que "os jovens têm sido proporcionalmente mais prejudicados no contexto da atual crise, e a desocupação tem hoje um perfil etário ainda mais desfavorável aos mais jovens do que no passado" (p. 561). Em face do desemprego juvenil, o percentual da contribuição dos filhos para a formação da renda familiar também se torna um agravante, podendo causar a precarização nas famílias, conforme já observado por Borges (2006).

No que se refere ao estado civil, $53 \%$, ou seja, um pouco mais que a metade dos participantes, são solteiros, seguidos de $34 \%$ de casados e os demais com outros vínculos, não havendo nenhum viúvo na amostra. A renda per capita dos respondentes ao período anterior ao desemprego variava entre um e três salários mínimos, não sendo observada nenhuma renda acima de nove salários mínimos entre os participantes.

Quanto ao número de filhos, houve bastante variação entre os respondentes, sendo que $41 \%$ não possuem filhos. Dos que possuem, a maioria possui dois filhos (correspondente a 28\% na população estudada). A presente variável reflete o peso da responsabilidade social como fator que medeia o impacto do desemprego sobre a afetividade dos trabalhadores, sobretudo no que se refere à participação no orçamento familiar.

O número de pessoas que residem com o participante da pesquisa varia de uma a sete pessoas, sendo $43 \%$ das famílias de uma a três pessoas e $51 \%$ de quatro a sete. Dos 100 participantes, 52\% assinalaram que não eram provedores de renda da casa e $48 \%$ pontuaram que eram. No enunciado sobre religião, a maioria dos participantes se declarou católica, com uma taxa de 48\%, seguidos de $35 \%$, que se disseram protestantes ou evangélicos. Por fim, 17\% assinalaram não possuir religião. Não houve apontamentos das religiões espírita e candomblé ou outras.

Quanto ao seguro desemprego, 41\% disseram já tê-lo recebido. A maioria (46\%) não recebeu e 13\% estão recebendo. Um dado que chama a atenção é que algumas pessoas que estão recebendo seguro estão em busca de um emprego sem a carteira assinada, pois, assim, segundo eles, podem continuar a receber o seguro desemprego. Verificou-se que a maioria dos entrevistados possui o ensino médio completo (56\%), seguidos de participantes que possuem o ensino superior, com $26 \%$. Esses dados revelam que os indicadores de desemprego na população estudada apresentaram índices de desocupação, com tendência a ser menor entre as pessoas com baixa escolaridade, e maior entre aquelas de escolaridade intermediária e superior.

Entre as variáveis que compõem esse aspecto sociodemográfico, compreende-se que a participação no orçamento e o número de filhos, correlacionados à responsabilidade por encargos financeiros, são as que evidenciam maiores riscos ao bem-estar psicológico dos respondentes. Isso decorre, sobretudo, em razão da impossibilidade de o desempregado prover o sustento familiar, implica no comprometimento de um dos fundamentos da sua identidade individual, uma vez que há um rompimento com compromissos produtivos e reprodutivos assumidos socialmente. Nessas situações, os impactos psicossociais se evidenciam na medida em que o desempregado se sente desamparado, impotente e incapaz de saciar suas necessidades sociais e de seus dependentes.

Na EASPSTD, foram analisadas a frequência, média e o desvio padrão (DP) do sofrimento psíquico e social. Os resultados apresentaram a média dos itens que correspondem ao sofrimento psíquico igual a 3,32 (DP = 1,29), com variação entre "às vezes" e "frequentemente", enquanto a média do sofrimento social foi de $1,84(\mathrm{DP}=0,98)$, variando entre "raramente" e "às vezes".

Com relação aos itens referentes ao fator sofrimento psíquico, da EASPSTD, pode-se observar a maior frequência nas respostas "sempre" nos enunciados: "sinto-me envergonhado porque gostaria de poder ajudar nas despesas de casa"; "tenho me sentido muito triste porque não estou trabalhando"; "percebo que a falta de emprego me deixa estressado", com destaque para o temor em não conseguir arrumar outro emprego, conforme dados do Gráfico 1. 
Gráfico 1: Demonstrativo da frequência de respostas do fator sofrimento psíquico

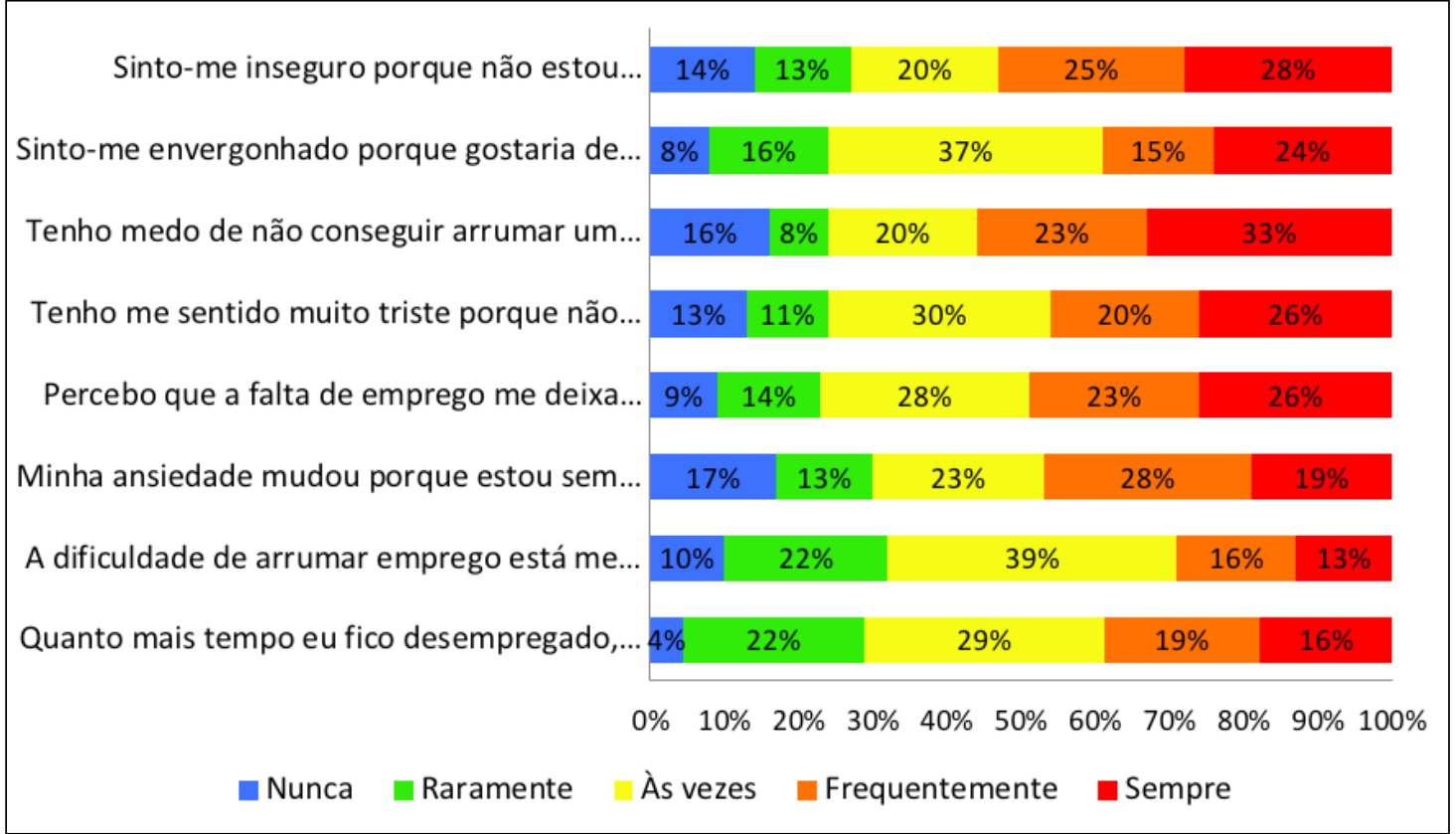

Os resultados das frequências de respostas dos enunciados da dimensão sofrimento social confirmam a concepção de Dejours (2003) de que a preocupação da maioria das pessoas com a situação do desemprego é a miséria, daí a origem do medo. A situação relativa ao medo de não conseguir arrumar trabalho se torna atemorizante, uma vez que o mercado é volátil.

Histórias de desemprego de longa duração e de situações em que o trabalhador não consegue mais voltar para o mercado formal se repetem. E mais, aquele que consegue voltar ao mercado formal tem até mais medo, porque já conhece as consequências do desemprego (Castelhano, 2005, p. 17).

Para Dejours (1992), o desemprego possui uma imagem de negatividade na sociedade e, segundo ele, essa situação expõe a identidade do trabalhador em uma atualidade em que o trabalho é excessivamente valorizado e concebido como um dever moral. "O medo e a angústia agravam o sofrimento mental. À medida que diminui a segurança no emprego, o medo abre uma porta para o sofrimento" (Castelhano, 2005, p. 15).

Sentir-se envergonhado na situação de desemprego foi um dos enunciados também mais apontados. Isso revela a ideologia defensiva da vergonha, a qual resulta da ansiedade dirigida não contra uma angústia proveniente de conflitos intrapsíquicos de natureza mental e, sim, de ter que lutar contra um perigo e um risco reais (Dejours, 1992).

Dejours, Abdoucheli e Jayet (1994) definem as estratégias defensivas como mecanismos pelos quais o trabalhador busca modificar, transformar e minimizar a percepção da realidade que o faz sofrer. Os autores concebem que há diferença entre um mecanismo de defesa individual e um coletivo, sendo que no primeiro permanece sem a presença física do objeto, que se encontra interiorizado. Já o segundo depende da presença de condições externas e se sustenta no consenso de um grupo específico de trabalhadores.

Oliveira e Mendes (2014), estudando estratégias defensivas em desempregados, observaram que essas aparecem mais relacionadas "às defesas de adaptação, no qual o sujeito nega seu sofrimento, adaptando-se a ele” (p. 397). Mendes (2007) associou essa defesa de negação à interiorização e naturalização das vivências de sofrimento produzidas em comportamentos de desconfiança, isolamento e individualismo. 
Evidenciam-se, nas respostas dessa dimensão, os principais danos psicossociais relacionados à situação de não trabalho, dentre os quais: estresse, ansiedade insegurança e medo. Pinheiro e Monteiro (2007), refletindo sobre desemprego e agravos à saúde mental, destacam quatro fases de possível evolução embasados nas propostas de Lira e Weinstein (1985), citados por SeligmannSilva (1994):

Fase 1: Reação do indivíduo que busca soluções para seu desemprego mas já demonstra alguns sintomas, como mudança de humor e insônia.

Fase 2: Esta fase caracteriza-se pela transição, na qual presencia-se desânimo, tristeza e o início de um processo de isolamento.

Fase 3: A adaptação patológica frente à situação é a terceira fase, sendo que pode ocorrer o alcoolismo.

Fase 4: Caracterizada pelo embotamento afetivo e a deterioração da autoimagem, acentuando o desalento.

$\mathrm{Na}$ dimensão da escala referente ao sofrimento social, as frequências pontuadas pelos participantes revelam que os respondentes apresentam poucos problemas familiares e poucas dificuldades na rede de contatos em decorrência do desemprego (Gráfico 2).

Gráfico 2: Demonstrativo da frequência de respostas do fator sofrimento social

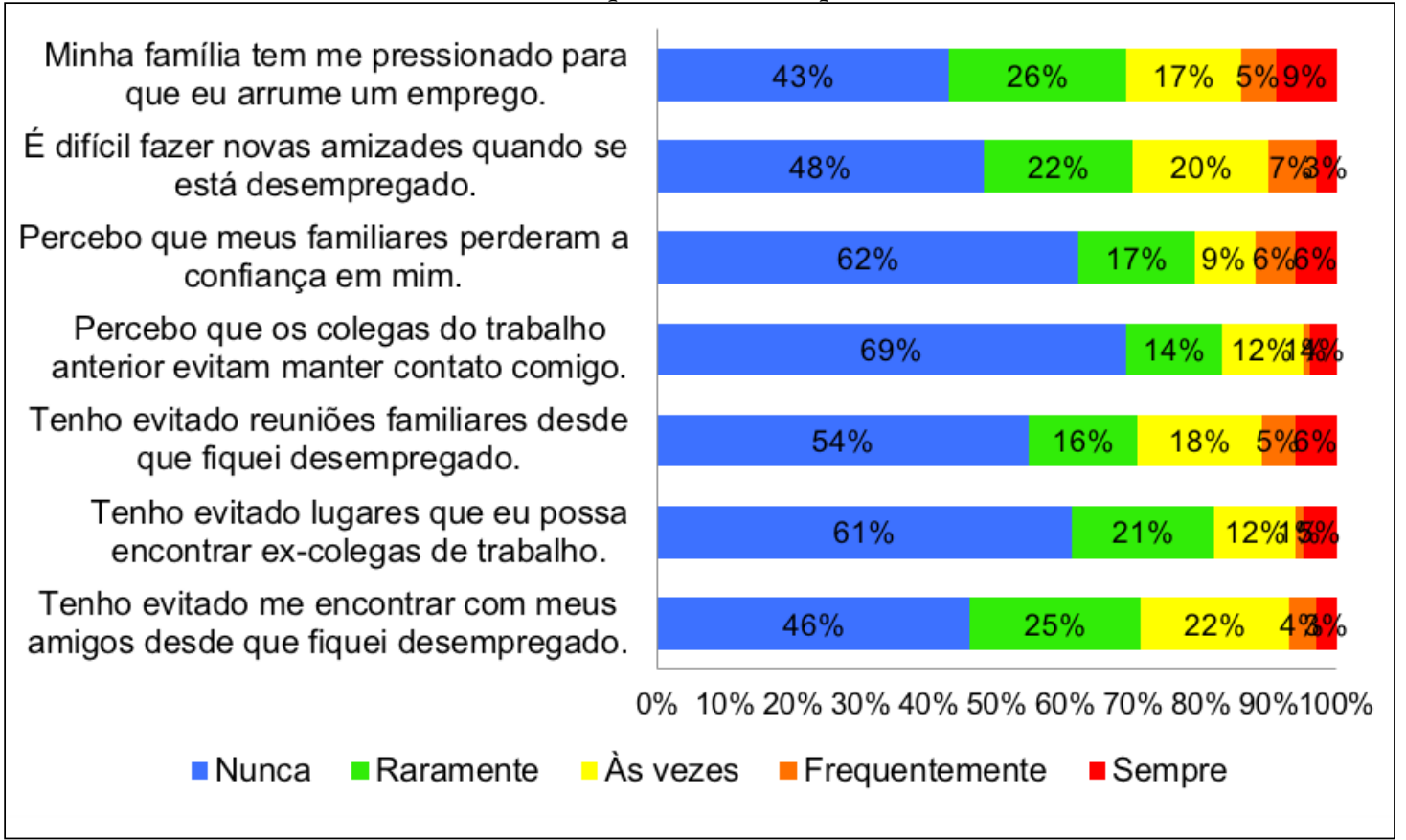

Os dados da dimensão sofrimento social denotam que o apoio social percebido na situação de desemprego apresentou frequências positivas em suas formas básicas: apoio material da família e apoio emocional da família e dos amigos. A nosso ver, compartilhar o sofrimento com demais pessoas que passam pela mesma vivência torna-se uma estratégia de ação importante para criação e fortalecimento de laços e redes em que os sujeitos possam ter apoio e suporte social. Uma pesquisa sobre as estratégias utilizadas pelos trabalhadores para enfrentar o desemprego revelou que "as estratégias de sobrevivência e de reinserção profissional estão baseadas na ativação das redes de amigos e de familiares" (Bendassolli, Coelho-Lima, Carlotto, Nüssle, \& Ferreira, 2015, p. 348).

Dejours (1992), em seus estudos sobre a psicodinâmica do trabalho, mostrou como as relações interpessoais interferem na motivação em exercer a atividade laboral e também na saúde do trabalhador. 
De acordo com Fonseca e Moura (2008), o apoio social também permite o compartilhamento de emoções e sentimentos com familiares, amigos ou grupos que ofereçam um apoio afetivo, emocional. Ainda, segundo esses autores, o apoio social influencia de forma significativa a saúde do trabalhador e, quando há apoio social suficiente, ocorre certa "absorção" de parte dos efeitos adversos do ambiente, o que, consequentemente, pode vir a minimizar o desencadeamento de patologias (Fonseca \& Moura, 2008).

Com base nos resultados, podemos observar, nesta pesquisa, que o desemprego provoca consequências psicológicas nos desempregados, conforme resultados da dimensão sofrimento psíquico. Porém, ao observarmos os da dimensão sofrimento social, as frequências do impacto foram menos expressivas. A nosso ver, isso pode estar associado ao perfil sociodemográfico dos respondentes (faixa etária de 19 a 41 anos), média do tempo em que se encontram desempregados (11,7 meses) somada à possibilidade de suporte social entre amigos e familiares, sendo possíveis fatores protetivos para amenizar as consequências sociais do desemprego nesse grupo estudado.

Em face às condições de (des)proteção social (Cardoso Junior, 2015) causadas pelo desemprego, "uma das áreas-chave em termos de políticas públicas para proteger a saúde mental passa por evitar o sobre-endividamento e assegurar aos afetados por este problema uma rápida ajuda que lhes permita regressar a uma vida digna" (Antunes, 2015, p. 274). O autor considera também que "os investimentos em políticas públicas de emprego diminuem o impacto da recessão na saúde mental das populações amortecendo as suas consequências negativas e diminuindo os riscos de suicídio" (p. 267).

Seligmann-Silva (2015) também ressalta a necessidade emergente da criação de políticas públicas e iniciativas da sociedade como forma de enfrentamento dos males causados pelo desemprego na subjetividade e saúde. E, como bem pontuado pela autora, tais ações, logicamente, devem ser somadas à criação de empregos e outras formas de geração de renda em prol do fortalecimento dos pertencimentos. Isso se faz necessário, posto que, diante dessas situações, o trabalhador passa a vivenciar "mais sofrimento patogênico em detrimento do sofrimento criativo, sendo o primeiro relacionado à desvalorização, inutilidade e improdutividade" (Oliveira \& Mendes, 2014, p. 389).

Nos resultados desta pesquisa, os participantes revelaram apresentar poucos problemas familiares ou ter poucas dificuldades na rede de contatos. $O$ apoio social percebido na situação de desemprego apresentou frequências positivas nas formas básicas de apoio social: apoio material da família, apoio emocional da família e dos amigos.

Notadamente, diante do desmonte do sistema de proteção social acarretada pelo desemprego, faz-se mister ações voltadas à mobilização coletiva de luta pelo emprego visando contribuir para minimizar o sofrimento vivenciado pelos desempregados. Barros e Mendes (2003) asseguram que a coesão entre eles e os relacionamentos satisfatórios atuam como estratégias para manutenção do equilíbrio psíquico perante as adversidades da situação do desemprego. Segundo os autores, as estratégias individuais e coletivas utilizadas parecem servir para evitarem o adoecimento e se manterem sadios.

Goulart (2003), em pesquisa realizada junto ao Movimento dos Trabalhadores Desempregados (MTD), verificou que as articulações psicossociais no engajamento do movimento social era uma das possibilidades de superar o desemprego, bem como amenizar o medo diante dessa situação.

Esta pesquisa permitiu compreender a ligação entre o desemprego e o impacto na saúde mental dos trabalhadores desempregados, além de evidenciar que o cenário se configurar numa questão psicossocial, no qual a:

Psicologia é convocada a compor a rede de forças de combate ao desemprego, trazendo uma visão psicossocial do desemprego, analisando seus impactos nas pessoas e nas relações intersubjetivas e propondo estratégias, a partir do seu cabedal construído de teorias e técnicas (Ribeiro, 2009, p. 343). 
Sato (2013) reconhece haver nesse cenário um espaço para atuações da Psicologia Social, com seus aportes teóricos e métodos que possibilitam dar visibilidade à realidade. Nesse panorama, a Psicologia do Trabalho também necessita se preocupar com a situação do desemprego em decorrência do sofrimento psíquico e social, devendo atuar em intervenções voltadas para elaboração de atividades relacionadas ao investimento na formação profissional dos trabalhadores, enquanto atividades educativas, como uma estratégia de promoção da saúde. Estudos têm mostrado resultados que evidenciaram diferenças significativas no que concerne à auto percepção de saúde mental dos trabalhadores em virtude da sua frequência em programas de formação profissional, indicando melhor situação entre os que frequentam cursos, sejam homens ou mulheres, sejam empregados ou desempregados (Oliveira, Pinto \& Barros, 2014).

Por sua vez, as atuações na área da Psicologia Clínica poderão operar criando espaços de escuta e acolhimento, de modo a nortear, orientar e fortalecer as estratégias de defesa psicológicas dos desempregados para o enfrentamento dessa fase difícil em suas vidas. Nessa linha de pensamento, concorda-se com Abs e Monteiro (2010) que:

As práticas da psicologia clínica em face do sofrimento psíquico causado pelo desemprego contemporâneo de que antes de sanar o patológico, o terapêutico tem de abrir possibilidade à criatividade em ruptura a toda a serialização vigente, sendo o terapêutico, comprometido com certa plasticidade inerente à vida, acompanhando-a e cuidando dela em sua constante instabilidade (p. 426).

Além disto, vale ressaltar que:

O aumento do desemprego está associado a um aumento das taxas de suicídio. Os grupos mais vulneráveis são particularmente afetados em épocas de crise econômica. Os efeitos das crises econômicas podem ser mitigados. Investimentos em políticas ativas de emprego diminuem o impacto da recessão na saúde mental das populações amortecendo as suas consequências negativas e diminuindo o suicídio (Antunes, 2015, p. 267).

Conforme descrito por Schmidt (2004), "talvez a psicoterapia possa ocupar, como uma referência entre outras possíveis, esse espaço de separação e recolhimento, esse lugar de repouso e suporte, num momento de perigo e risco para uma clientela que se encontra desalojada" (p. 9). Assim sendo, concorda-se com Antunes (2015) que sistemas fortes de proteção social tornam as sociedades mais aptas a resistir às adversidades.

Por fim, os resultados desta pesquisa reafirmam as ponderações de que o fenômeno do desemprego:

Pressiona a Psicologia a rever suas bases teóricas e metodológicas, levando-a a se aproximar de pressupostos que integrem os elementos históricos, sociais e culturais no modo de compreender e investigar a experiência humana. Isso ocorre na medida em que a vivência do desemprego por parte dos trabalhadores concatena, inalienavelmente, dimensões objetivas e subjetivas (Coelho-Lima, Costa \& Bendassolli, 2013, p. 1295).

Mediante o exposto e como já observado por Sato e Schmidt (2004), conclui-se que a psicologia tem muitas contribuições para auxiliar no enfrentamento dos impactos produzidos pelo desemprego, o que será possível mediante uma profícua articulação entre a prática da psicologia clínica (pautada no suporte psicoterápico) e as intervenções provenientes da Psicologia Social e do Trabalho. 


\section{Conclusões}

Os resultados obtidos permitiram confirmar que o desemprego pode gerar uma desorganização e desagregação na identidade construída pelo indivíduo, trazendo consequências à sua saúde mental e às relações sociais que dele decorrem convergindo com os resultados de outros estudos anteriormente elencados.

Após a análise de todos os dados obtidos, chegou-se à conclusão de que o fator psíquico é mais afetado pelo desemprego. Sentimentos de vergonha, incapacidade, tornar-se dependente de alguém ou de uma ajuda foram as principais consequências geradas pelo desemprego entre os participantes deste estudo. Ao analisar os dados, foi possível concluir que o fator social é afetado de forma mais branda, já que em situação de desemprego, a família e os amigos ajudam e servem de apoio e motivação para o indivíduo desempregado ir em busca de um novo trabalho.

Embora o estudo tenha tido como limitação o pequeno número de participantes e a falta de associações entre variáveis, o que certamente traria mais informações sobre o tema, a análise dos resultados das dimensões da escala evidenciaram que, no grupo estudado, o fator psíquico é mais afetado pelo desemprego, em função dos enunciados mais pontuados como sentimentos de vergonha, incapacidade e medo. No que tange o fator social, os dados são menos expressivos, estando por sua vez, associados ao apoio familiar e de amigos.

Outra limitação observada diz respeito ao instrumento utilizado, pelo fato dos enunciados da escala na "dimensão social" incluírem apenas as relações sociais próximas (família, amigos) e não as condições macro e mesossociais, que produzem o desemprego. Desse modo, os resultados não permitiram fazer uma análise dialética, uma vez que o sofrimento social tem relação com a estrutura social, sendo o sofrimento psíquico consequência do sofrimento social (no sentido amplo).

Com os resultados desta pesquisa na devolutiva ao responsável pelo PAT, apresentaremos como contribuições estratégias de políticas públicas para o enfretamento da situação de desemprego na região estudada, além da formação de grupos com os desempregados a serem oferecidos nas dependências do próprio PAT, a fim de criar propostas conjuntas para o enfretamento do desemprego.

\section{Agradecimentos}

Agradecemos a Fundação de Amparo à Pesquisa do Estado de São Paulo (Fapesp) pela Bolsa de Iniciação Científica concedida a Caio Augusto Rodrigues Martins Januário, processo no 2017/0669475.

\section{Referências}

Abs, D. \& Monteiro, J. K. (2010). Práticas da psicologia clínica em face do sofrimento psíquico causado pelo desemprego contemporâneo. Psicologia em Estudo, 15 (2), 419-426.

Antunes, J. A. P. J. (2015). Crise económica, saúde e doença. Psicologia, Saúde e Doenças, 16 (2), 267-277.

Antunes, R. (2004). O avesso do trabalho. São Paulo: Expressão Popular.

Antunes, R. (2011). Os modos de ser da informalidade: rumo a uma nova era da precarização estrutural do trabalho? Serviço Social e Sociedade, (107), 405-419.

Argolo, J. C. T. \& Araújo, M. A. D. (2004). O impacto do desemprego sobre o bem-estar psicológico dos trabalhadores da cidade de Natal. Revista de Administração Contemporânea, 8 (4), 161-182.

Aucher, L. \& Barnier, F. (2015, May 22). Lentreprise de dépossession: entretien avec Daniéle Linhart. La Vie des Idées. Recuperado em 20 fevereiro de 2019, de http://www.laviedesidees.fr/Lentreprise- de-depossession-3054.html. 
Barros, C. A. \& Oliveira, T. L. (2009). Saúde mental de trabalhadores desempregados. Revista Psicologia: Organizações e Trabalho, 9 (1), 86-107.

Barros, P. C. R. \& Mendes, A. M. B. (2003). Sofrimento psíquico no trabalho e estratégias defensivas dos operários terceirizados da construção civil. Psico-USF, 8 (1), 63-70.

Bendassolli, P. F., Coelho-Lima, F., Carlotto, M. S., Nüssle, F. S., \& Ferreira, I. M. (2015). Estratégias utilizadas pelos trabalhadores para enfrentar o desemprego. Revista Colombiana de Psicología, 24 (2), 347-362.

Bernardo, M. H., Nogueira, F. R. C., \& Büll, S. (2011). Trabalho e saúde mental: repercussões das formas de precariedade objetiva e subjetiva. Arquivos Brasileiros de Psicologia, 63 (spe), 83-93.

Borges, A. (2006). Impactos do desemprego e da precarização sobre famílias metropolitanas. Revista Brasileira de Estudos de População, 23 (2), 205-222.

Caldana, A. C. F. \& Figueiredo, M. A. C. (2002). Desemprego e subjetividade: estratégias de inclusão social e sobrevivência. Paidéia, 12 (22), 19-26.

Cardoso Junior, J. C. (2015). Trabalho, proteção social e desenvolvimento. Estudos Avançados, 29 (85), 87-103.

Castel, R. (1998). As metamorfoses da questão social: uma crônica do salário. Petrópolis, RJ: Vozes.

Castelhano, L. M. (2005). O medo do desemprego e a(s) nova(s) organizações de trabalho. Psicologia e Sociedade, 17 (1), $14-20$.

Coelho-Lima, F., Costa, A. L. F., \& Bendassolli, P. (2013). A produção científica da psicologia brasileira acerca do desemprego. Universitas Psychologica, 12 (4), 1283-1299.

Dejours, C. (1992). A loucura do trabalho: estudo em psicopatologia do trabalho (5a ed.). São Paulo: Cortez e Oboré. (Trabalho original publicado em 1987)

Dejours, C. (2003). A banalização da injustiça social. Rio de Janeiro: Editora FGV.

Dejours, C., Abdoucheli, E., \& Jayet, C. (1994). Psicodinâmica do trabalho: contribuições da escola dejouriana à análise da relação prazer, sofrimento e trabalho. São Paulo: Atlas.

Dimas, I. M., Pereira, M. D., \& Canavarro, M. C. (2013). Ajustamento psicossocial, ajustamento diádico e resiliência no contexto de desemprego. Análise Psicológica, 31 (1), 3-16.

Druck, G. (2011). Trabalho, precarização e resistências: novos e velhos desafios? Caderno CRH, 24 (spe1), 37-57.

Enriquez, E. (1999). Perda do trabalho, perda da identidade. Cadernos da Escola do Legislativo, 5 (9), 53-73.

Figueiredo, V. C. N. \& Nascimento, B. R. (2015). Sofrimento psíquico-social de mulheres desempregadas no contexto de trabalho precarizado. Estudos do Trabalho, 8 (15). Recuperado em 20 fevereiro de 2019, de: http://www. estudosdotrabalho.org/RRET\%2015\%2003.pdf.

Fonseca, I. S. S. \& Moura, S. B. (2008). Apoio social, saúde e trabalho: uma breve revisão. Psicologia para América Latina, (15). Recuperado em 20 fevereiro de 2019, de: http://pepsic.bvsalud.org/scielo.php?script=sci_ arttext\&pid=S1870-350X2008000400012.

França, M. H., Barreto, S. M., Pereira, F. G., Andrade, L. H. S. G., Paiva, M. C. A. \& Viana, M. C. (2017). Mental disorders and employment status in the São Paulo Metropolitan Area, Brazil: gender differences and use of health services. Cadernos de Saúde Pública, 33 (9), e00154116.

Furtos, J. (2007). Les effets cliniques de la souffrance psychique d'origine sociale. Mental'idées, (11), 24-33.

Furtos, J. (2008). Les cliniques de la précarité: contexte social, psychopathologie et dispositifs. Paris: Elsevier Masson.

Goulart, P. M. (2003). Sem medo do desemprego: o caso do movimento dos trabalhadores desempregados. Psicologia e Sociedade, 15 (1), 137-160.

Instituto Brasileiro de Geografia e Estatística (c2018). Pesquisa nacional por amostra de domicílio contínua. Brasília, DF: Autor. Recuperado em 20 fevereiro de 2019, de: https://biblioteca.ibge.gov.br/index.php/biblioteca-catalogo?vie $\mathrm{w}=$ detalhes\&id $=72421$.

Jacques, P. (2004). Souffrance psychique et souffrance sociale. Pensée Plurielle, 2 (8), 21-29.

Mendes, A. M. (2007). Da psicodinâmica à psicopatologia do trabalho. In A. M. Mendes (Org.), Psicodinâmica do trabalho: teoria, método e pesquisa (pp. 29-48). São Paulo: Casa do Psicólogo.

Mészáros, I. (2006). Desemprego e precarização: um grande desafio para esquerda. In R. Antunes (Org.), Riqueza e miséria do trabalho no Brasil (Vol. 1, pp. 27-44). São Paulo: Boitempo. 
Navarro, V. L. \& Padilha, V. (2007). Dilemas do trabalho no capitalismo contemporâneo. Psicologia e Sociedade, 19 (spe.), 14-20.

Oliveira, J. E. V., Pinto, J. F. V. C., \& Barros, R. M. A. (2014). A formação profissional e a percepção de saúde mental dos trabalhadores: estudo comparativo em situação de (des)emprego. Revista Brasileira de Saúde Ocupacional, 39 (129), 111-118.

Oliveira, J. N. \& Mendes, A. M. (2014). Sofrimento psíquico e estratégias defensivas utilizadas por desempregados: contribuições da psicodinâmica do trabalho. Temas em Psicologia, 22 (2), 389-399.

Pinheiro, L. R. S. \& Monteiro, J. K. (2007). Refletindo sobre desemprego e agravos à saúde mental. Cadernos de Psicologia Social do Trabalho, 10 (2), 35-45.

Pochmann, M. (2006). Desempregados do Brasil. In R. Antunes (Org.), Riqueza e miséria do trabalho no Brasil (pp. 59. 73). São Paulo: Boitempo.

Ribeiro, M. A. (2009). Estratégias micropolíticas para lidar com o desemprego: contribuições da psicologia social do trabalho. Psicologia Política, 9 (18), 331-346.

Sato, L. (2013). Recuperando o tempo perdido: a psicologia e o trabalho não regulado. Cadernos de Psicologia Social do Trabalho, 16 (spe1), 99-110.

Sato, L. \& Schmidt, M. L. S. (2004). Psicologia do trabalho e psicologia clínica: um ensaio de articulação focalizando o desemprego. Estudos de Psicologia, 9 (2), 365-371.

Schmidt, M. L. S. (2004). Clínica psicológica, trabalho e desemprego: considerações teóricas. Cadernos de Psicologia Social do Trabalho, 7, 1-10.

Seligmann-Silva, E. (1994). Destaque mental no trabalho dominado. Rio de Janeiro: Editora UFRJ; Cortez.

Seligmann-Silva, E. (2015). Desemprego e desgaste mental: desafio às políticas públicas e aos sindicatos. Revista Ciências do Trabalho, (4), 89-109.

Simões, P. H. C., Alves, J. E. D., \& Silva, P. L. N. (2016). Transformações e tendências do mercado de trabalho no Brasil entre 2001 e 2015: paradoxo do baixo desemprego? Revista Brasileira de Estudos de População, 33 (3), 541-566.

Terra, C. P., Carvalho, J. A. S., Azevedo, J. E. A., Venezian, L. A., \& Machado, S. B. (2006). Desemprego: discurso e silenciamento: um estudo com clientes de um serviço de aconselhamento psicológico. Cadernos de Psicologia Social do Trabalho, 9 (1), 33-51.

Veiga, H. M. S. \& Silva, N. I. A. (2007). Construção de escala para avaliar sofrimento psíquico-social de trabalhadores desempregados. Avaliação Psicológica, 6 (1), 13-20.

Werlang, R. \& Mendes, J. M. R. (2013). Sofrimento social. Serviço Social e Sociedade, (116), 743-768.

\section{Endereço para correspondência}

mlschmidt@uol.com.br, caiojanuario29@gmail.com,

lilianemorandi@yahoo.com.br
Submetido em: 14/10/2018

Revisado em: 14/02/2019

Aprovado em: 11/03/2019 